\title{
Intracranial meningiomas and neurofibromatosis type 2
}

\author{
Gokcen Gokce • Osman Melih Ceylan • \\ Fatih Mehmet Mutlu • Halil Ibrahim Altinsoy
}

Received: 4 March 2014 / Accepted: 7 March 2014 /Published online: 21 March 2014

(C) Springer-Verlag Wien 2014

Dear Editor,

We read with great interest the study by Aboukais et al. [1] describing the characteristics of intracranial meningiomas and neurofibromatosis type 2 (NF 2). On the basis of our experience, there is another important point that should be mentioned.

Meningiomas are slow-growing tumors, and they are mostly asymptomatic for a patient's entire life. Meningiomas occur in about half of NF 2 patients, and they are often multiple [4]. Barrett et al. [2] and Prasad et al. [5] reported that recurrent third nerve palsy could be the presenting feature of NF 2 . We reported a similar case of a 57-year-old man with recurrent alternating oculomotor nerve palsy secondary to a parasagittal meningioma [3]. It is possible that these high-grade meningiomas related to NF 2 can cause a form of neuromyotonia or meningioma-associated mediators may trigger an inflammatory reaction combined with vasculopathy leading to oculomotor neuropathy. We recommend that all NF2 patients should be investigated to diagnose a possible oculomotor nerve disorder secondary to meningioma in the follow-up period.

Conflicts of interest None.

\section{References}

1. Aboukais R, Zairi F, Baroncini M, Bonne NX, Schapira S, Vincent C, Lejeune JP (2013) Intracranial meningiomas and neurofibromatosis type 2. Acta Neurochir (Wien) 155:997-1001

2. Barrett VJ, Tan MH, Elston JS (2012) Recurrent third nerve palsy as the presenting feature of neurofibromatosis 2. J Neuroophthalmol 32: 329-331

3. Gokce G, Ceylan OM, Altinsoy HI (2013) Recurrent alternating oculomotor nerve palsy: an unusual presentation of parasagittal meningioma. Neuro-Ophthalmology 37:82-85

4. Goutagny S, Kalamarides M (2010) Meningiomas and neurofibromatosis. J Neurooncol 99:341-347

5. Prasad M, Choi J, Baxter P (2014) Recurrent third nerve palsy as the presenting feature of neurofibromatosis 2 . J Neuroophthalmol 34:102103

\footnotetext{
G. Gokce $(\bowtie)$

Department of Ophthalmology, Sarikamis Military Hospital,

Kars, Turkey

e-mail: drgokcengokce@gmail.com

O. M. Ceylan

Department of Ophthalmology, Ardahan Military Hospital,

Ardahan, Turkey

F. M. Mutlu

Department of Pediatric Ophthalmology and Strabismus, Gulhane

Military Medical Academy, Ankara, Turkey

H. I. Altinsoy

Department of Pediatric Ophthalmology and Strabismus, World Eye

Hospital, Ankara, Turkey
} 